\title{
A NEW HEXASTYLIS (ARISTOLOCHIACEAE) WITH UNCERTAIN ORIGIN \\ IN THE SOUTHEASTERN U.S.A., DISCOVERED THROUGH SOCIAL MEDIA
}

\author{
Brian R. Keener \\ University of West Alabama \\ Biological and Environmental Sciences \\ Livingston, Alabama 35470, U.S.A. \\ bkeener@uwa.edu
}

\author{
Gena Todia \\ Wetland Resources Environmental Consulting \\ Fairhope, Alabama 36532, U.S.A. \\ jaget@zebra.net
}

\section{ABSTRACT}

A new species of Hexastylis-H. rollinsiae-is herein described from cultivated material with uncertain origin. The discovery was facilitated through social media.

\section{RESUMEN}

Una nueva especie de Hexastylis- - H. rollinsiae-se describe aquí a partir de material cultivado de origen incierto. El descubrimiento se facilitó a través de las redes sociales.

\section{INTRODUCTION}

Hexastylis Raf. (Aristolochiaceae) is a genus of primitive flowering plants composed of evergreen, terrestrial, acaulescent herbs endemic to the southeastern United States. The recognition of Hexastylis as a distinct genus from Asarum L. is controversial, but when treated separately, it contains 18-19 taxa including the one described here (Keener 2020; Weakley 2020; Weakley \& Poindexter 2020).

The path of discovery for the new entity was unconventional. The junior author is an avid gardener of native plants in the landscape around her home in Baldwin County, Alabama. The garden contains many "rescued plants" from lands slated for development within her primary environmental consulting service area of south Alabama and sometimes surrounding states. In May 2019, in a shaded perennial bed where Hexastylis arifolia (Michx.) Small and H. harperi (Gaddy) B.R. Keener \& L.J. Davenp. were cultivated, a third entity was noticed that did not resemble either species. Perplexed by the oddly shaped flowers, she ultimately sought to crowdsource the identification by posting photos on Facebook in the special interest group "Flora of the Southeastern United States" (Todia 2019). The senior author determined from the images the entity had a distinctive morphology and likely represented an undescribed species of Hexastylis. Together we surveyed the area most likely to be the original source of the cultivated material and found it to be transformed by development. Additional searches of nearby areas with suitable habitat were also unsuccessful. Because of these circumstances, we describe the new taxon from cultivated material.

\section{TAXONOMIC TREATMENT}

Hexastylis rollinsiae B.R. Keener \& Todia, sp. nov. (Figs. 1, 2). TYPe: U.S.A. Alabama: Baldwin Co.: from cultivation, Fairhope, garden of Gena \& Jay Todia, 22 May 2021, Brian R. Keener 12,225 with Gena Todia \& Fred Nation (HOLOTYPE: UWAL).

Similar to Hexastylis speciosa R.M. Harper and H. finzelii B.R. Keener. Differs from both species by the longer stiffly erect to ascending pedicels positioning the flower well above the substrate (vs. shorter lax pedicels positioning the flowers at substrate level or resting on other flowers). Differs from $H$. finzelii by the recurved calyx lobes (vs. erect), greenish yellow style appendages (vs. maroon). Differs from $H$. speciosa by the gradual flaring of calyx tube near middle and gradual constriction above middle (vs. abruptly flaring near middle and not constricting above middle), calyx without a ring of numerous maroon and greenish yellow stripes (vs. striped).

Terrestrial acaulescent herbs from short rhizomes and long stolons. Leaves: petioles to $14 \mathrm{~cm}$ long; blades hastate-sagittate with rounded basal lobes to sometimes triangular to less commonly almost cordate; leaves 5-10.5 cm long by 5-10 cm wide. Flowers: peduncle erect to ascending, 6-9.5 cm long, usually recurved near 

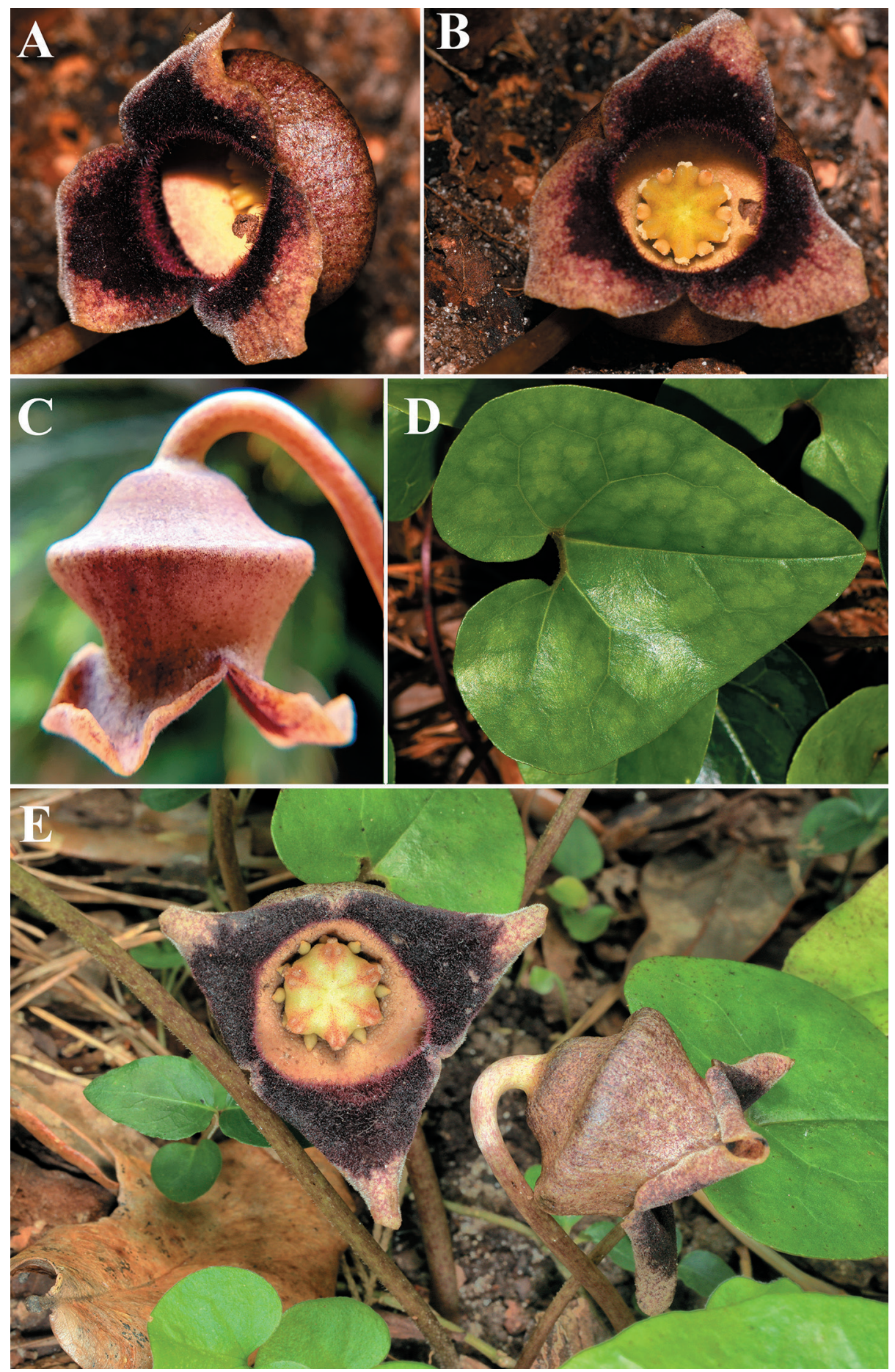

FIG. 1. Hexastylis rollinsiae B.R. Keener \& Todia. A. Flower, oblique view. B. Flower, front view, showing greenish yellow style and style appendages. C. Flower, side view showing recurved pedicel D. Leaf. E. Flower, front and side view. Photos A, B, and D by Brian Finzel; photo C by Brian Keener; photo E by Alan Cressler. 


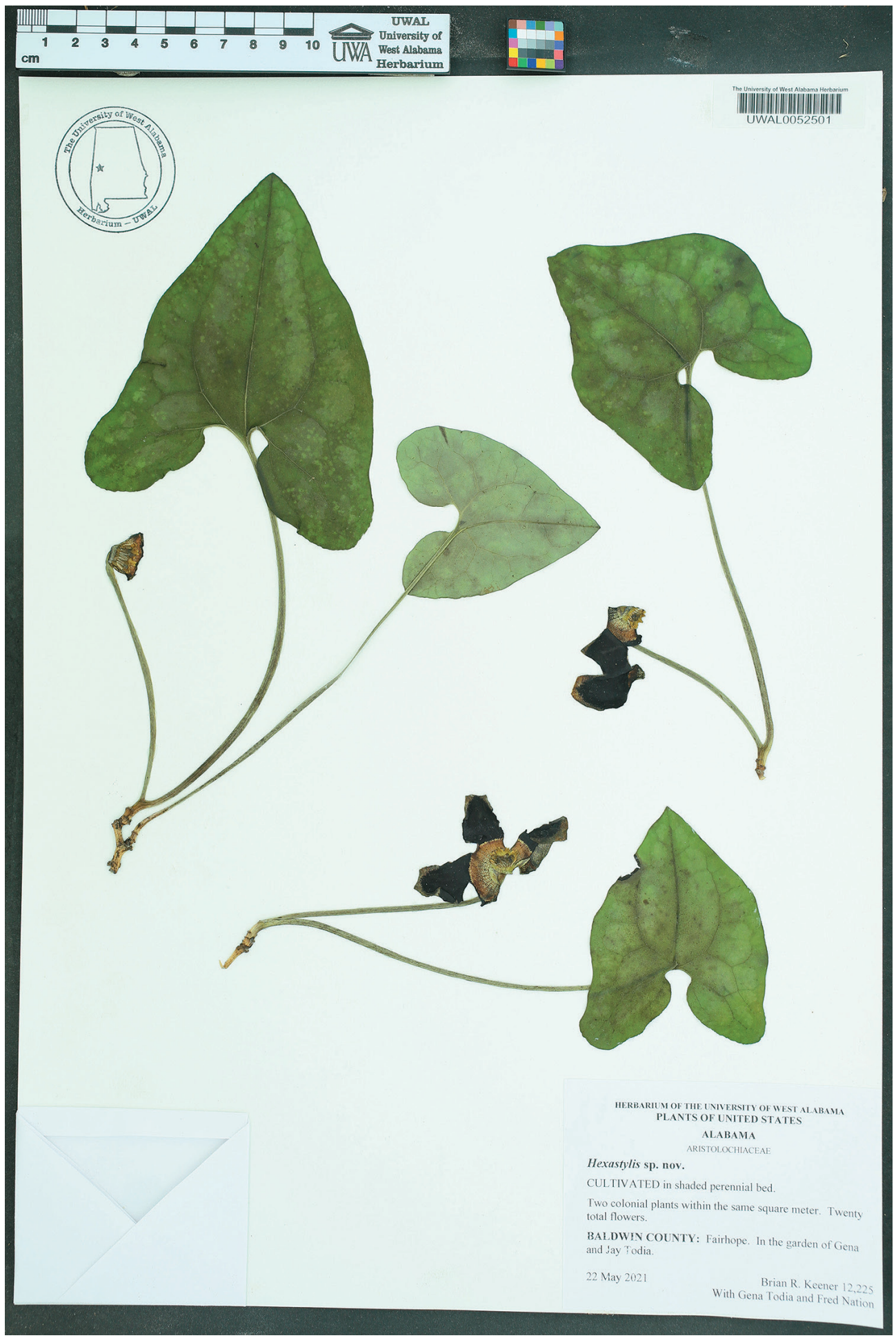


tip; Calyx 28-33 mm long (from base to lobe tip), $25 \mathrm{~mm}$ wide; tube in two parts divided by a gradual outward flare to about the middle and a gradual constriction above the middle, the lower tube to ca. $10 \mathrm{~mm}$ long, broadly funnel-form, about as long as the upper tube; upper tube similar in shape to the lower but reversed, ca. $10 \mathrm{~mm}$ long; lobes three, spreading, broadly triangular, about as wide as long, 18-20 mm long, 18-20 mm wide; apices obtuse. Stamens 12, to $3.1 \mathrm{~mm}$ long, theca extrorse, $2.0-2.6 \mathrm{~mm}$ long, connective $0.5 \mathrm{~mm}$ prolonged above theca. Styles greenish yellow; extensions bifid to stigma (at least at late anthesis), rounded, 1.0-1.5 mm long; stigma round to elliptic ca. $1.0 \mathrm{~mm}$ tall, ca. 1.5 wide.

Additional specimens examined: From Cultivation. U.S.A. ALABAMA: Baldwin Co.: Fairhope, 13 May 2019, Gena Todia s.n. (ALNHS, UWAL); 29 Apr 2020, Brian R. Keener 11,767 with Gena Todia, Fred Nation, Richard \& Nancy Cobb (UWAL).

Distribution and habitat.-To date, Hexastylis rollinsiae is known only from two plants in cultivation at a private residence in Baldwin County, Alabama, U.S.A.

Etymology and Common Name.-The epithet honors Gertrude Madeline Gaylord Rollins (1918-1991), longtime resident of Dothan, Alabama, maternal grandmother to Gena Todia, and inspiration for Gena's love of plants. We propose the literal translation combined with the layman's vernacular of related species be employed for the common name, "Rollins' Wild Ginger."

KEY TO SPECIES OF THE ARIFOLIA-SPECIOSA GROUP

1. Calyx urceolate, without an outward flare near middle dividing the calyx tube into distinct lower and upper portions

H. arifolia

(complex)

1. Calyx campanulate-cylindric or cup-shaped with an abrupt or gradual outward flare dividing the tube into distinct lower and upper portions.

2. Calyx lobes erect; style appendages maroon

H. finzelii

2. Calyx lobes spreading to recurved; style appendages greenish yellow.

3. Inside of calyx with numerous and well defined yellow and maroon stripes oriented toward the center of flower; pedicels lax causing flowers to rest on substrate or on top of other flowers, not recurved near base of flower; orifice of flowers usually facing laterally to ascending related to plane of substrate

3. Inside of calyx without stripes; pedicels stiff, ascending to erect thus holding flowers well above substrate but recurved near base of flower; orifice of flowers usually nodding and facing substrate

\section{DISCUSSION}

Hexastylis rollinsiae is a remarkable new species in the genus with a tenuous future. Presently, the total known existence of $H$. rollinsiae consists of two patch-forming plants within the same one square meter in the Todia garden. The plants were first noticed in 2019 when three flowers were observed, followed by two flowers in 2020, and 20 flowers in 2021. As previously mentioned, H. rollinsiae is cultivated with H. harperi and H. arifolia, or possibly an unnamed stoloniferous entity of the complex. The possibility that $H$. rollinsiae arose through in situ hybridization was strongly considered. However, we rejected this hypothesis because H. rollinsiae does not appear to be morphologically intermediate in leaf or flower morphology while demonstrating characteristics not seen in either of the other taxa.

In fact, Hexastylis rollinisae exhibits a unique suite of morphological characters, some characters new for the genus. Perhaps the most distinctive character is the presence of stiffly erect to ascending pedicels positioning the flower well above the ground but recurved near the tip forcing the flower opening towards the substrate. This feature is unknown in any other Hexastylis species. The pedicels of all other Hexastylis species are weaker and/or shorter, allowing the flower to rest on the substrate or on top of other flowers with the flower opening horizontal to the substrate plane or ascending to about 70 degrees.

Most Hexastylis species form distinct clumps, but Hexastylis rollinsiae appears to be stoloniferous, forming larger patches. This feature is known in Hexastylis harperi and two unnamed entities in the H. arifolia complex including the "Buck Creek" entity (Weakley 2020) and one in southeast Alabama. In his description of $H$. harperi [as H. shuttlerworthii var. harperi Gaddy], Gaddy (1987a) found that plants would sometimes produce a shoot in the area a flower would normally be produced. This shoot developed into a "shallow rhizome" allowing clonal growth and patch formation. It is possible the same mechanism is in place for H. rollinsiae and 
the other entities. Unfortunately, due to the limited available material of $H$. rollinsiae, this character could not be assessed other than the observation of patch formation.

Another morphological consideration is the external shape of the calyx. In Hexastylis rollinsiae, the calyx, as viewed from the side, gradually flares outward from the base to near the middle, but above the middle, it gradually constricts below the lobes. This character is dramatically different from those of species believed to be close relatives in the genus. The calyces of Hexastylis speciosa and $H$. finzelii have an abrupt flare and are unconstricted above the middle. The shape of the H. rollinsiae calyx is perhaps most similar to $H$. contracta Blomquist, a species that has very few other morphological similarities and is most likely distantly related in the genus. (Blomquist 1957; Gaddy 1987b).

Hexastylis rollinsiae appears most closely allied with H. speciosa and H. finzelii (Fig. 3), Alabama endemics and members of the "Speciosa" group concept established by Blomquist (1957). These three taxa, along with the H. arifolia complex (see key above), share a leaf mottling pattern of lighter green areas between the veins and distinct (though sometimes short) style extensions. These similarities are in stark contrast to rest of the genus, Blomquist's "Virginica" group, which bear a leaf-mottling pattern with lighter green along the primary veins and paired style extensions that are fused.

In light of the recent discoveries of Hexastylis rollinsiae and $H$. finzelii, along with other problematic populations difficult to assign to a species, the genus is poised for a fresh molecular investigation utilizing some of the more modern whole genomic techniques. Only then will the relationships within the genus become more certain.

\section{Uncertain origin}

At this time, the exact location of the original material is ambiguous. However, based on limited evidence, we believe the most likely source is a location in Coffee County, Alabama, within the city limits of Enterprise. The evidence for this is based partly on the memory of the junior author who conducted field work there in early 2011 as well as an entry in her personal notes that she extracted "Hexastylis arifolia" and "Rhododendron canescens" from the location when it was clear that development was eminent. The date of extraction was 5 Feb 2011. Thus, the Hexastylis would not have been in flower and would have been impossible to recognize its distinctive and defining floral characters. The precise locality is along the E side of Indian Camp Creek, just S of the jct. between US Hwy 84 (Boll Weevil Cir.) and AL Hwy 27 at approximately the following coordinates: 31.327728, -85.837751. On 12 May 2019, eight days after the post on Facebook (Todia 2019), both authors visited the location. As previously mentioned, the location was found to have been tremendously altered by development and no Hexastylis plants were found. On the same day, we proceeded to survey downstream along Indian Camp Creek on the north side of US Hwy 84 where woods were present and less disturbed. At this location, Hexastylis was discovered in great abundance, but all flowering individuals were identifiable with the $H$. arifolia complex. These individuals were stoloniferous and forming patches similar to the $H$. arifolia (and H. rollinsiae) in the Todia garden, which was expected due to the known extraction event in 2011 less than 0.5 mile upstream. We returned to the site on 15 May 2021 for a more thorough survey, which again proved unsuccessful.

Due to unsuccessful searches, it is possible (though unlikely) that the original source of the Hexastylis rollinsiae is from a different location altogether, one which the junior author does not remember and did not record in her personal notes. If this is true, we do not have any leads for an alternative location at this time.

\section{Discovered through social media}

It is worth noting that this discovery facilitated through social media appears to be the first for a plant species in North America. However, other new plant species discovered via social media have involved at least three different taxa from other continents. These include Drosera magnifica P. Gonella, Thunbergia kasajauna Bh. Adhikari \& J.R.I. Wood, and Begonia joshii P.W. Moonlight, R. Hollands, A. Cano, and D.A. Purvis (Gonella et al. 2015; Moonlight 2020). Additional discoveries of new species through social media include two arthropods (Winterton et. al 2012; Pfingstl et al. 2021), one fungus (Santamaria et al. 2020), and one lichen (Jatnika 


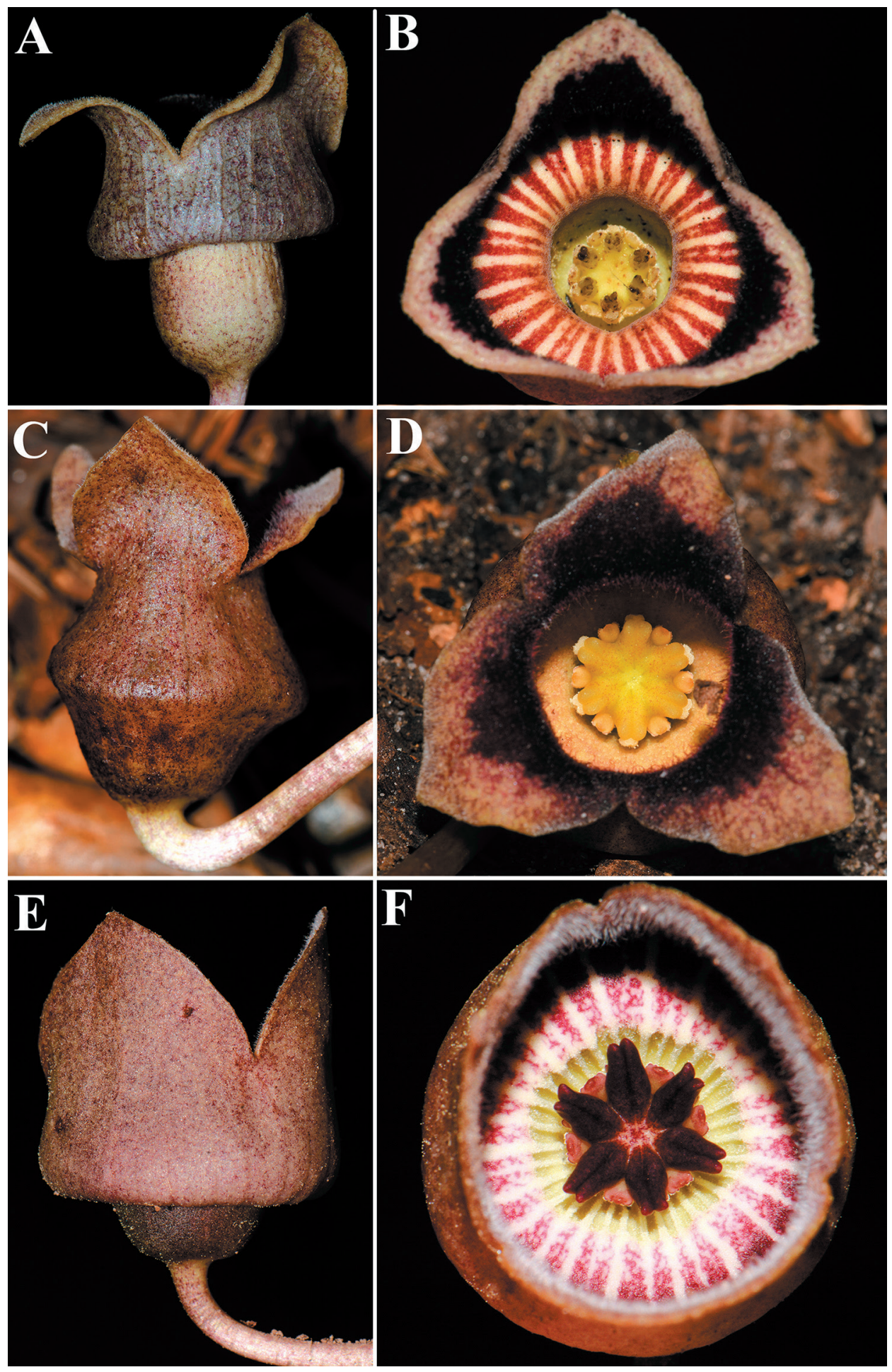


et al. 2019). Of all these discoveries, only the fungal species occurs in North America (Ohio). It is expected that these types of discoveries will continue to increase due to the common usage of smart phones with cameras coupled with the numerous available social media and citizen science platforms.

\section{Going forward}

We chose to move forward with the description and naming of Hexastylis rollinsiae despite the many lingering questions that surround this new taxon. We felt that the publication would inspire others to search for extant wild populations leading to their discovery. In the meantime, in order to safeguard the future existence of the species, certain plant conservation organizations will be chosen to grow and propagate H. rollinsiae so that a potential traumatic event at the single current location of cultivation would not eliminate the species.

\section{ACKNOWLEDGMENTS}

We appreciate Brian Finzel and Alan Cressler for making photo collections available for study and use for this publication. We are grateful to John Clark for his help with the design of the photo plates. We are appreciative of Emma Ryan, Molly Moon, Fred Nation, and Eric St. Clair for technical support. We thank Wayne Barger (ALNHS) for a specimen loan. We thank Richard and Nancy Cobb, and Elizabeth Cox for help with the surveys. We appreciate Bill Finch and Joan Rundles for a preliminary review and critique. We thank Alvin Diamond (TROY) and Larry Davenport (SAMF) for thorough reviews of the manuscript. And most of all, we thank Jay Todia for helping to obtain these and other plants from the wild and for his immeasurable role in the Todia garden.

\section{REFERENCES}

BLomQuist, H.L. 1957. A revision of Hexastylis of North America. Brittonia 8:255-281.

GADDY, L.L. 1987a. Hexastylis shuttleworthii var. harperi (Aristolochiaceae), a new variety of heartleaf from Alabama and Georgia. Sida 12:51-56.

GADDY, L.L. 1987b. A review of the taxonomy and biogeography of Hexastylis (Aristolochiaceae). Castanea 52:186-196. Gonella, P.M., F. Rivadavia, \& A. Fleischmann. 2015. Drosera magnifica (Droseraceae): The largest New World sundew, discovered on Facebook. Phytotaxa 220(3):257-267.

Jatnika, M.F., G. WeErakoon, O. ArachCHIGE, I.S.Noer, A. VoytsekHovich, \& R. Lücking. 2019. Discoveries through social media and in your own backyard: Two new species of Allographa (Graphidaceae) with pigmented lirellae from the Palaeotropics, with a world key to species of this group. Lichenologist 51:227-233.

KEENER, B.R. 2020. A new species of Hexastylis (Aristolochiaceae) from northeast Alabama (U.S.A.) with notes on the species "groups" within the genus. J. Bot. Res. Inst. Texas 10:315-323.

MoonLIGHT, P. 2020. "Finding new species on social media." Botanic Stories, Royal Botanic Garden Edinburgh, Scotland, 8 Jun 2020, https://stories.rbge.org.uk/archives/33585. Accessed 16 Jul 2021.

PfingstL, T., S.F. Hiruta, T. Nemoto, W. Hagino, \& S. Shimano. 2021. Ameronothrus twitter sp. nov. (Acari, Oribatida) a new coastal species of oribatid mite from Japan. Spec. Diversity 26:96-99.

Santamaria, S., H. Enghoff, \& A.S. Reboleira. 2020. The first Laboulbeniales (Ascomycota, Laboulbeniomycetes) from an American millipede, discovered through social media. Mycokeys 67:45-53.

TodiA, G. 2019. Flora of southeastern United States, "Hexastylis....ID...?" Facebook, 4 May 2019, 8:36 PM, https://www. facebook.com/groups/874315202585568/posts/2707459829271087. Accessed 12 July 2021.

WEAKLEY, A.S. 2020. Flora of the southeastern United States (Edition of 20 Oct 2020). North Carolina Botanical Garden, Chapel Hill, U.S.A. http://www.herbarium.unc.edu/flora.htm

WeAKLEY, A.S. \& D.B. Poindexter. 2020. Continued recognition of Hexastylis, with two species transferred to Hexastylis from Asarum. In: Weakley, A.S., D.B. Poindexter, H.C. Medford, B.A. Sorrie, C.A. McCormick, E.L. Bridges, S.L. Orzell, K.A. Bradley, H.E. Ballard, Jr., R.N. Burwell, S.L. Lockhart, and A.R. Franck. 2020. Studies in the vascular flora of the southeastern United States. VI. J. Bot. Res. Inst. Texas 14:199-240.

Winterton, S., H.P. Guek, \& S. Brooks. 2012. A charismatic new species of green lacewing discovered in Malaysia (Neuroptera, Chrysopidae): The confluence of citizen scientist, online image database and cybertaxonomy. ZooKeys 214 (214):1-11. doi:10.3897/zookeys.214.3220. PMC 3426877. PMID 22936863 